\title{
Low carbon economy and agricultural development
}

\author{
Qian Liu ${ }^{1, a *}$, Zhili $\mathrm{Xu}^{2, \mathrm{~b}}$,Zhengyang $\mathrm{Hao}^{3, \mathrm{c}}$ \\ ${ }^{1}$ Hohai University Nanjing, Jiangsu \\ ${ }^{3}$ Hohai University Nanjing, Jiangsu \\ ${ }^{2}$ Hohai University Nanjing, Jiangsu
}

\begin{abstract}
With the continuous development of China's industry, we improve the economy at the same time, also has a certain impact on the environment, and agriculture and the environment have a direct relationship. Therefore, it is necessary to develop low-carbon economy, which is an important way to promote agriculture forward. However, there are still some problems in the development of low-carbon agriculture in China, which need people to actively study, not only need to innovate technology, but also need to improve the system. This paper first describes the content of low-carbon agriculture, and then describes the development model of lowcarbon agriculture in China, understand the problems in the development, and finally explain the development strategy, to provide reference for relevant researchers.
\end{abstract}

\section{INTRODUCTION}

In the process of social development, all kinds of greenhouse gases emitted by people's production and activities make global temperature warming. In order to solve this problem, low-carbon economy appears in people's vision. Low carbon economy is to reduce the use of non renewable energy and greenhouse gas emissions by means of innovative technology and industrial transformation, so as to ensure economic development and better environmental protection. And fundamentally speaking, greenhouse gases will have a great impact on agricultural development, so we should develop lowcarbon economy in agriculture and transform it into lowcarbon agriculture, so as to promote the sustainable development of agriculture.

\section{CONTENT OF LOW CARBON AGRICULTURE}

Low carbon agriculture is to reduce the air pollution gas as its goal, adapt to the corresponding advanced technology, through improving the infrastructure construction, adjusting the industrial structure and other methods, so as to achieve low energy consumption and high efficiency development of agriculture. Use the least material to get the maximum economic benefits[1]. Reduce all kinds of resources, including human resources and material resources, etc. in order to better reduce the impact of agriculture on the environment at various stages, and give full play to the role of agriculture in carbon sequestration.

\section{DEVELOPMENT SITUATION OF LOW CARBON AGRICULTURE}

\subsection{Saving and substitution}

In the process of agricultural production, in order to increase products, chemical fertilizers, pesticides and other products will be used. Although these products can well increase crop products, if they are not used properly, they will cause serious pollution, and will remain on crops, affecting people's health [2]. In addition, in the process of agricultural production, a large number of water resources and energy will also cause environmental pollution. Therefore, reducing chemical pesticides and saving water resources, through the use of corresponding methods to replace, has become an important method in the development of low-carbon agriculture.

The first is to reduce the use of agricultural, chemical fertilizer and other chemicals. In reducing chemical fertilizer, soil testing and formula technology can be used to better save chemical fertilizer. In order to ensure the ideal effect of chemical fertilizer use, it can also save chemical fertilizer better. Organic fertilizer can also be used to replace chemical fertilizer, which can not only improve soil nutrients, but also optimize soil structure [3]. In terms of pesticides, we can use biological control methods to reduce the use of pesticides, through biological control to solve the existing problems of diseases and insect pests, or use biological pesticides, such as Bacillus thuringiensis, white stiff army and other antibiotics, which can not only eliminate pests, but also improve the resistance of crops. Second, save water resources. In the process of agricultural development, water conservation

\footnotetext{
a* Corresponding author: 1863810129@hhu.edu.cn

b Corresponding author: 1943733503@qq.com

${ }^{\mathrm{c}}$ Corresponding author: 1863810126@hhu.edu.cn
} 
can be carried out from several aspects. For example, we can water crops regularly according to their own habits, or cultivate cold resistant crops. We can also use drip irrigation, sprinkler irrigation and other methods to replace flood irrigation. In terms of energy conservation, we can use the current advanced equipment to save energy and promote no tillage cultivation. In addition, it can be replaced by energy. For example, the use of solar energy, wind energy and so on, to reduce the production of fossil fuel, through this method can reduce the greenhouse gas emissions of non renewable energy, better environmental protection.

\subsection{Three dimensional cultivation and cleaner production}

Through three-dimensional planting and breeding, we can absorb sunlight, land, air and so on, so as to better improve the growth space of organisms, reduce the waste of land resources, increase crop products, and move the high-yield and efficient crop production effect. Reasonable planting of other industries among crops, rice cultivation, symbiosis of crabs and other methods are important manifestations of three-dimensional agriculture [4]. Clean production is the production of waste materials in crop processing, so as to reduce environmental pollution and improve the utilization rate of renewable resources. For example, the use of corn straw back and forth, increase soil nutrients, not directly burned, and then can reduce the impact on the environment.

\section{Problems in the deVelopment of LoW CARBON AGRICULTURE}

On the basis of more and more attention to environmental issues in the world, low-carbon agriculture is a kind of efficient production agriculture, which can help agriculture to develop towards low-carbon environmental protection, expand agricultural industrial chain, and improve agricultural production technology and capacity, so as to better meet the actual demand for agricultural products in China, and promote the healthy development of agriculture. However, from the perspective of current development, although China has achieved certain results, it still faces some problems.

\subsection{The level of agricultural modernization is not high}

Due to the influence of traditional agriculture in China, the mode of production is still mainly artificial. Most of the agriculture has not realized modernization, and its mechanization level is not high, so it is unable to centralize the management of agriculture. Agriculture characterized by the distribution of small-scale farmers will lead to various waste in the production process, thus increasing greenhouse gas emissions [5]. Traditional agricultural production methods need more heat than modern agriculture, and they still use extensive production mode. In order to obtain more economic benefits, farmers do not pay attention to environmental protection. In the production process, in order to improve crop products, excessive increase of pesticides will affect soil fertility, destroy soil structure, and gradually form a vicious circle, which will seriously pollute the environment and hinder agricultural development.

\subsection{The technical level is low}

From the current development process of low-carbon agriculture, we can see that its low-carbon agricultural technology level is low, lack of independent innovation. This is because the research and development of agricultural technology in China is relatively implemented, and there are not many scientific researchers who can engage in this field, and there are fewer researchers who can really send out the actual investigation in rural areas, which can not meet the current agricultural requirements for science and technology [6]. At the same time, the conversion rate of low-carbon agricultural scientific research achievements is low. Although there are more than 5000 kinds of agricultural scientific research achievements in China every year, less than 1500 kinds can be used in actual agricultural production. In addition, due to the low level of culture in rural areas and the lack of publicity and education on agricultural development, farmers' own innovation ability is insufficient. Moreover, due to the low professional level of farmers, they do not pay enough attention to low-carbon aspects and can not make corresponding scientific research and technology circulate in rural areas.

\subsection{Lack of perfect management system}

From the point of view of the government, the governments and relevant departments in various regions have not invested much in agriculture, and there is no corresponding perfect system. First of all, although our country is gradually paying attention to agriculture, and is gradually giving funds, but more emphasis is on improving agricultural production and farmers' economic benefits, lack of attention to the environment, which leads to the lack of positive implementation of the basic facilities for environmental protection of agricultural production, more lack of protection technology for agricultural environment, to the development of lowcarbon agriculture The exhibition has a certain impact. Secondly, all kinds of systems have not been improved [7]. For example, the property rights system of resources and environment is not perfect. Agricultural resources belong to the collective, while individuals are entitled to use them. In order to improve their own economic benefits, the users will have destructive development on agricultural production and seriously affect the rural environment. Moreover, there is a lack of environmental protection system in rural areas. Although there are relevant laws, they are not really implemented. Finally, the government's propaganda for low-carbon agriculture is insufficient. Some farmers themselves have a low level of education and lack of awareness of low carbon. In addition, they may realize that if they apply low-carbon agriculture, they will increase the cost of agricultural production to a certain 
extent, and then they will not consciously carry out the development of low-carbon agriculture in the production process, which will lead to the negative implementation of low-carbon agriculture. In addition, in the process of developing low-carbon agriculture in China, there is not much communication with foreign countries, because the development of low-carbon agriculture in China is relatively late, lack of advanced technology, and there is a gap with some developed countries, so that in the short term, low-carbon agriculture can not achieve the desired results.

\section{DEVELOPMENT STRATEGY OF LOW CARBON AGRICULTURE}

\subsection{Developing technology intensive agriculture}

In the process of developing low-carbon agriculture, technological innovation is the key. Only through advanced technology can we ensure low-carbon agriculture, and at the same time enable farmers to obtain more economic benefits [8]. First of all, we should actively improve the level of rural education, train relevant scientific research personnel, and should be able to encourage existing researchers to study agricultural production work more deeply, and stimulate agricultural research and innovation ability. Secondly, we should also improve the conversion rate of agricultural scientific research achievements, and truly implement the research and development achievements into agricultural production. In this, the relevant departments must carry out training and guidance on agriculture, through such a method, the technical level of agriculture can be significantly improved, and then all kinds of resources can be reasonably used to realize the common development of low-carbon agricultural economy and social benefits. At the same time, in the process of agricultural production, the relevant departments should also introduce foreign advanced technology, so as to better promote the continuous development of China's agriculture, and ensure the direct and harmonious development of rural areas, farmers and agriculture. In the process of improving the quality of farmers, we need to be able to carry out education according to the actual situation of their own region. The government should send professional technical personnel to the field for guidance, so as to really play a technical role and also play a role in low-carbon agricultural publicity. At the same time, this method can be better accepted by farmers, thus promoting the development of low-carbon agricultural production, and play a protective role.

\subsection{Improve relevant systems}

First of all, the local government should be able to actively promote low-carbon agriculture, formulate relevant systems according to the local actual situation, and develop it according to the process, so as to promote the development of low-carbon agriculture, as shown in Figure 1. The government should increase publicity efforts to improve the awareness of low-carbon agriculture, so that farmers can more consciously accept low-carbon agricultural technology in production. Secondly, in the process of promulgating relevant policies, the government should be able to clearly protect the environment and give certain financial support to use it for environmental protection construction and supporting agricultural environmental protection technology. Through the method of levying resources and environmental taxes on the users of resources and environment, enterprises can be guided to actively research and develop agricultural scientific research achievements and effectively apply them. Finally, the government should be able to improve the relevant system. According to the actual situation of agricultural resources to classify, for the resources with strong public welfare, then we should be able to effectively combine the ownership and the right to use, and for agricultural resources, we need to effectively separate the ownership and use rights. It is not only necessary to actively improve and formulate the rural environmental laws, but also to actively implement the existing laws and improve their practicability, so as to reduce environmental damage and better protect the environment in the process of agricultural development in rural areas.

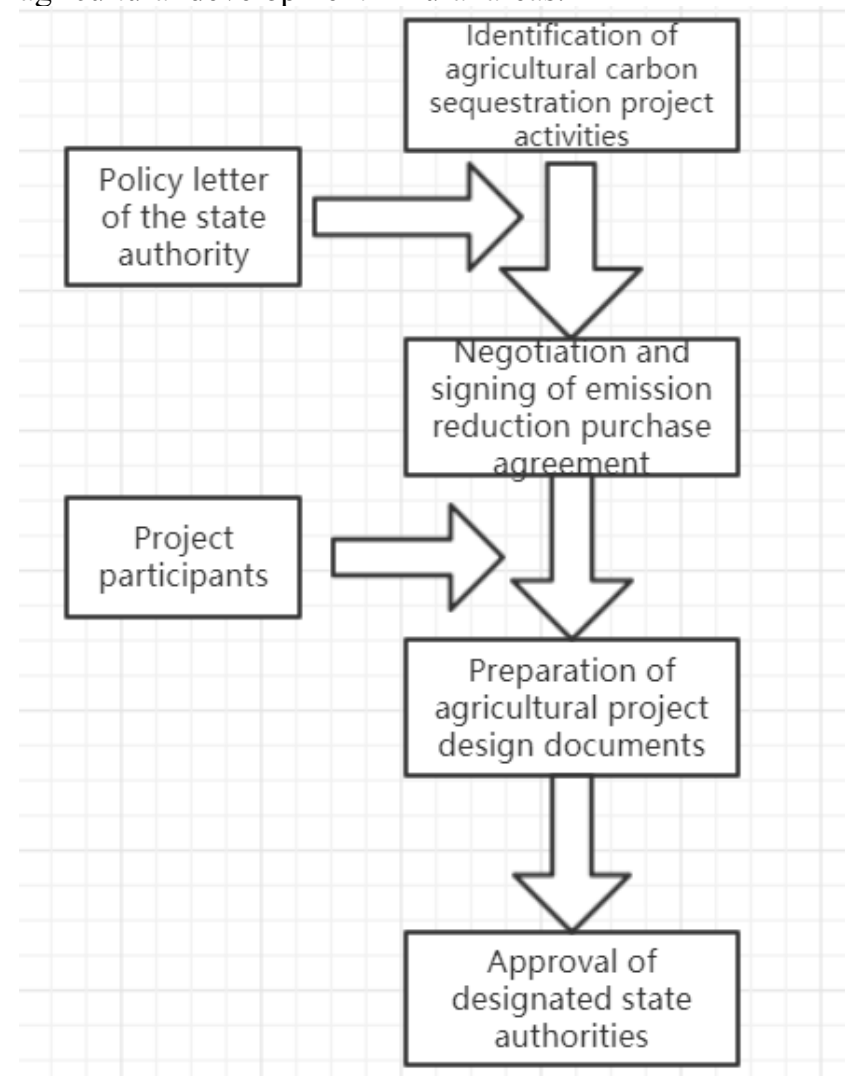

Figure 1. Development process of low carbon agriculture project

\subsection{Actively and internationally exchange and cooperation}

The reason for the lack of protection of the natural environment is that the understanding of low-carbon agriculture is not deep enough. Therefore, if we want to effectively promote the effective transformation of China's agricultural structure, we should be able to actively 
implement people's low-carbon awareness, and effectively communicate with the international community. By understanding the development of low-carbon agriculture in developed countries, we can realize the shortcomings of China's agriculture, and then integrate the development of our country to carry out effective optimization. At present, considering the characteristics of China's large population base and high food demand, if only relying on the current productivity, the demand can not be met. Therefore, we need to actively communicate with the international community. In the process of international exchange, we should be able to participate in the competition of carbon trading market, actively participate in the international exchange meeting of low-carbon agriculture, actively learn relevant advanced technology and management, and implement it in the agricultural grass-roots level, so that farmers can truly feel the benefits of low-carbon agriculture. In addition, we should be able to learn from the system of western developed countries, and then combine with the actual situation of our country to actively improve, so as to provide security for the development of low-carbon agriculture and reduce the cost of investment in controlling greenhouse gas emissions.

\section{ConClusion}

In short, agricultural development under low-carbon economy is an important method to effectively improve the level of agricultural economy and protect the ecological environment in China, which can provide help for the sustainable development of China's agriculture. Therefore, in the development, we need to be able to put forward specific solutions to the corresponding problems, in order to ensure that low-carbon agriculture can be carried out smoothly on the basis of better help China's social stable development.

\section{References}

1. Liang Yanan. Transformation and practice path of agricultural economic development under low carbon economy [J]. Fortune today, 2020 (19): 18-19.

2. $\mathrm{Hu} \mathrm{Yu}$. Analysis on the transformation of agricultural economic development mode under the background of low carbon economy [J]. Low carbon community, 2020,10 (07): 203-204.

3. Yu Linke. Transformation of agricultural economic development mode under the background of low carbon economy $[\mathrm{J}]$. Agricultural disaster research, 2020,10 (04): 187-188 + 190 .

4. Tian Hongcheng. Thinking on the transformation of agricultural economic development mode under the background of low carbon economy $[\mathrm{J}]$. Science and technology economy guide, 2020,28 (20): 227.

5. Liu Daokun. Thinking on the transformation of agricultural economic development mode under the background of low carbon economy [J]. Financial circles, 2020 (19): 28-29.
6. Wang songjuan. Approaches to the transformation of agricultural economic development mode in the era of low carbon economy [J]. Southern agricultural machinery, 2020,51 (12): 66Wang songjuan. Approaches to the transformation of agricultural economic development mode in the era of low carbon economy $[\mathrm{J}]$. Southern agricultural machinery, 2020,51 (12): 66 .

7. Liu Peng. Analysis on the transformation of agricultural economic development mode in the era of low carbon economy [J]. Shanxi agricultural economy, 2020 (08): 57-58.

8. Yang Yanfeng. Problems and Transformation Countermeasures of agricultural economic development under the background of low carbon economy $[\mathrm{J}]$. Modern agricultural science and technology, 2020 (07): $232+234$. 